\title{
Synthesis and Structural Characterization of Xanthate (KEX) in Sight of Their Utilization in the Processe s of Sulphides Flotation
}

\author{
Nedjar. Zohir*1 ${ }^{1}$ Bouhenguel. Mustapha ${ }^{2}$ and Djebaili Abd Elbaki ${ }^{3}$ \\ ${ }^{I}$ Engineering laboratory of Chemical and Process Engineering.Sciences and Engineer Faculty, Industrial \\ Chemistry Department, Med Khider Biskra University. ALGERIA \\ ${ }^{2}$ Engineering laboratory of Chemical and Process Engineering.Sciences and Engineer Faculty, Industrial \\ Chemistry Department,Med Larbi Ben Mhidi oum elbouaghi University. ALGERIA \\ ${ }^{3}$ Engineering laboratory of Chemical and Process Engineering.Sciences and Engineer Faculty, Industrial \\ Chemistry Department, L'hadj lakhdar Batna University. ALGERIA \\ E-mail*: zohirnedjar@yahoo.fr
}

\section{ABSTRACT}

A lot of industries (chemical, mining) developed numerous processes based on the use of the adsorption, From then on, the resolution of practice problems pass inevitably by the understanding of fundamental concepts governing the phenomena of flotation and the interaction in the solid-liquid or solid-gas interface.

In this study, we suggest proceeding to a theoretical and experimental study concerning the organic synthesis of an organo metallic product (KEX) by intermittent method and their use in the processes of sulphides flotation. Searches showed that the surface state after grinding resulted from a combination of oxidized sorts of sulfur treat type with copper sulphate and lead oxy-hydroxide thickness of which is very superior to $200 \mathrm{~nm}$. The addition of an organometallic molecule sulphurated (Potassium ethyl xanthate KEX) in available concentrations of $1 \mathrm{~g} / \mathrm{l}$ (6, $24.10^{-3} \mathrm{M}$ ) is going to lead the forming of an organometallic layer mixed in the galena surface. From weak concentrations in collector, the organometallic layer present in the mineral surface is mixed. It is formed by a complex xanthate type of lead (PbX, bandages IR in $\left.1200 \mathrm{~cm}^{-1}\right)$, of dixanthogene ( $X_{2}$ forms oxidized with the molecule of xanthate, bandages IR in $1262 \mathrm{~cm}^{-1}$ ), of elementary sulfur and a certain proportion of initial superficial oxidized phases. The mechanism leading to the forming of PbX is the type of ionic exchanges. On the other hand, two types of different mechanisms can be at the origin of dixanthogene forming $\left(X_{2}\right)$.

A first type consists of a catalytic oxidation in the mineral surface with reduction of the dissolved oxygen. This type of mechanism depends essentially on the potential redox of the system. A second type brings in the forming of xanthate salts of lead by a mechanism of Ionic exchange (eq. 1) then their catalytic degradation (eq. 2):

$\mathrm{Pb}^{n+}+n X \rightarrow(\mathrm{PbX})_{n} \quad$ Equation 1: independent from the potential rédox.

$\mathrm{Pb}(\mathrm{X})_{n}$ (catal. by $\left.\mathrm{PbS}\right)+1 / 2 \mathrm{O}_{2}+n / 2 \mathrm{H}_{2} \mathrm{O} \rightarrow \mathrm{Pb}(\mathrm{OH})_{n}+n / 2 \mathrm{X}_{2} \quad$ Equation 2: dependent on the redox potential.

Key Words: Flotation; Synthesis; Xanthate (KEX); Adsorption; Galena 


\section{PROBLEM}

A lot of industries (chemical, mining, developed numerous processes based on the use of the adsorption, what means in big part a good mastery of the superficial ability to react of the used solids. From then on, the resolution of practice problems pass inevitably by the understanding of fundamental concepts governing the phenomena of flotation and the interaction in the solidliquid or solid - gas interface.

The knowledge of the composition variations of the ore to be dealt, reproduces the concentration of the reagent in the pulp determine the results of the flotation. This research aims to better understand the phenomena of interaction (adsorption, haste,) of typical organic molecules thiols (Xanthate) on natural solid (sulphides).

The control and the regulation of the reagent concentration in the pulp is practically the only way of the establishment of an automatic system and an optimal regime of the reagent and an obtaining of a possible maximum of indication of flotation with a minimal consumption of the reagent of flotation $[1-10]$.

\section{METHODS AND STEPS}

In every case, the researches lean on a global approach of phenomena that is a consideration of the compartments set of the system and the links which unite them. This imposes the tools application of observation and description of interfaces on molecular and even atomic scales and so the same thing for the mechanisms of interaction in aqueous phase in systems of adsorbant / adsorbat. These two main approaches make by combining the techniques of adsorption robust liquid and the techniques of physical analyses of the solids surface. This approach is coupled with a study by physical tools of the surface state of adsorbants before and after contact. It is then necessary to be able to have non- destructive tools that information is of superficial origin by modulating the depth of investigation. Spectroscopy or molecular micro spectroscopy (Visible UV, infrared, RX) answer this contract conditions. It is important to be able to couple these techniques with a method of direct observation of the surface which is the electronic microscopy with sweeping (MEB) [11-14].

\section{MAIN RESULTS}

\subsection{Synthesis of Potassium Ethyl Xanthate (KEX) By the Discontinuous Method:}

During the intermittent method, in the basic solution of alcohol, consisted of a mole of éthylique alcohol, one mole of water and one mole of potassium hydroxide, one mole of disulfure of carbon $\left(\mathrm{CS}_{2}\right)$ was slowly added. After that, we separate the deposit of xanthate, which after addition of all the portion of disulfide of carbon representing constituent formed crystals. This method allows of obtaining of the high quality xanthates (superior activity of xanthates has $90 \%)[15-21]$. 


\subsection{Characterization of Used Collector: The Case of Potassium Ethyl Xanthate (KEX)}

\subsubsection{Characterization of potassium ethyl xanthate (KEX) synthetized with the electron microscope with sweeping (MEB):}

The principle of the sweeping consists in investigating the surface of the sample by successive lines and in passing on the signal of the detector to a cathode-ray screen sweeping of which is exactly synchronized with the one of the incidental bundle. Under the impact of the electron beam accelerated, diffused retro electrons and secondary electrons emitted by the sample are collected selectively by detectors which transmit a signal to a cathode ray tube whose sweeping is synchronized with the sweeping of the object (Figure 1) [22].

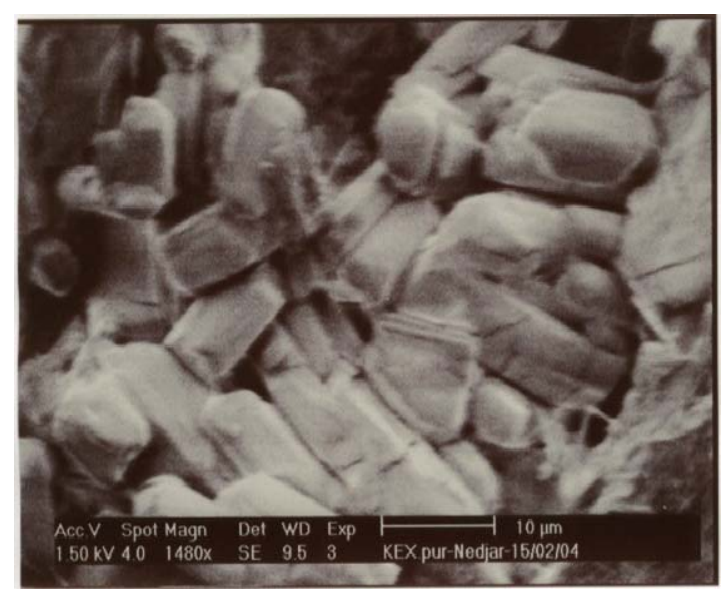

Fig. 1. Microphotography taken with the electron microscope with sweeping (X1480) for KEX.

\subsubsection{Characterization of synthesized potassium ethyl xanthate (KEX) by X-Ray :} This method is used to identify the nature and the structure of the crystallized products. Figure 2 shows intense reflexions with $2 \theta=11,81$ and $2 \theta=37,96$.

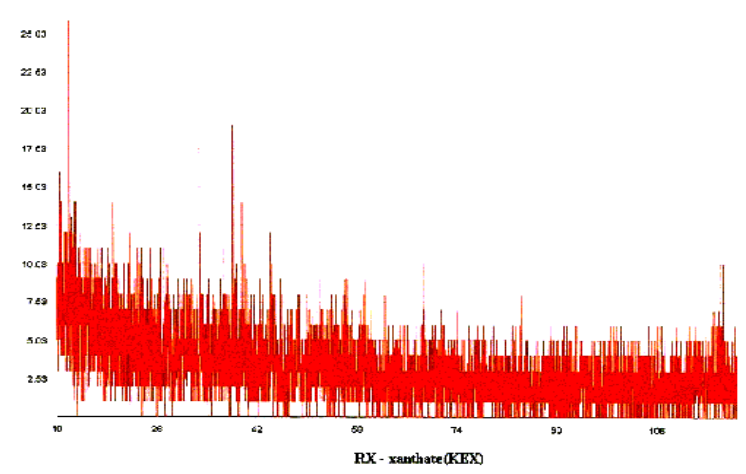

Fig. 2. Spectre RX of potassium ethyl xanthate synthetized. 


\subsubsection{Characterization of synthesized potassium ethyl xanthate (KEX) by infra-red spectroscopy:}

The infra-red synthesized ethyl xanthate spectrum (Figure 3 ) indicates the appearance of the absorption bands to 1147.44-1120.44-1050.87-1006.66 $\mathrm{cm}^{-1}$ and other bands to 1438.64 $1380.78-1295.93-1250.58 \mathrm{~cm}^{-1}$ allotted respectively to the vibrations of connections $(\mathrm{C}=\mathrm{S})$ and (O-CS) [30].

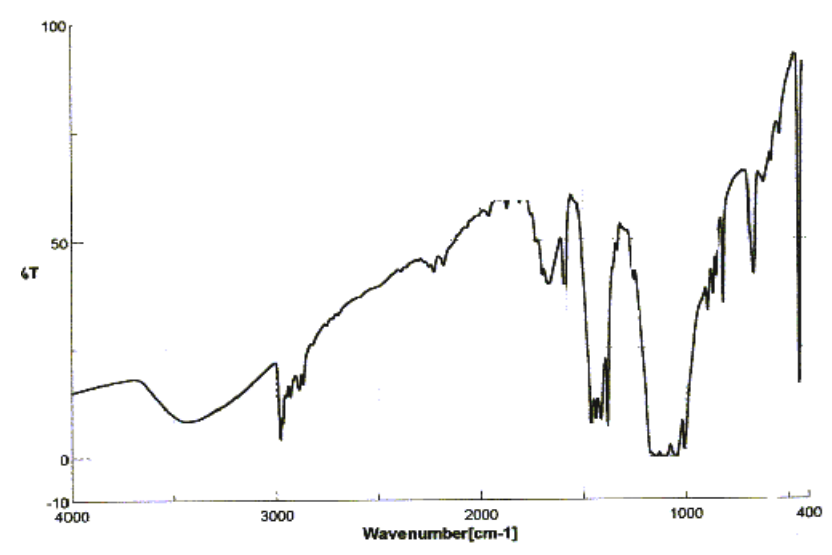

Fig. 3. Spectre FTIR of KEX synthetized.

\subsubsection{Characterization of potassium ethyl xanthate (KEX) by RMN1 H:}

Spectrum RMN1 H of synthesized KEX (Figure 4) is characterized by the presence of the peaks towards $1.37 \mathrm{ppm}$ of grouping methyl $\left(-\mathrm{CH}_{3}\right)$ and $4.45 \mathrm{ppm}$ of grouping $\left(-\mathrm{CH}_{2}\right)$.

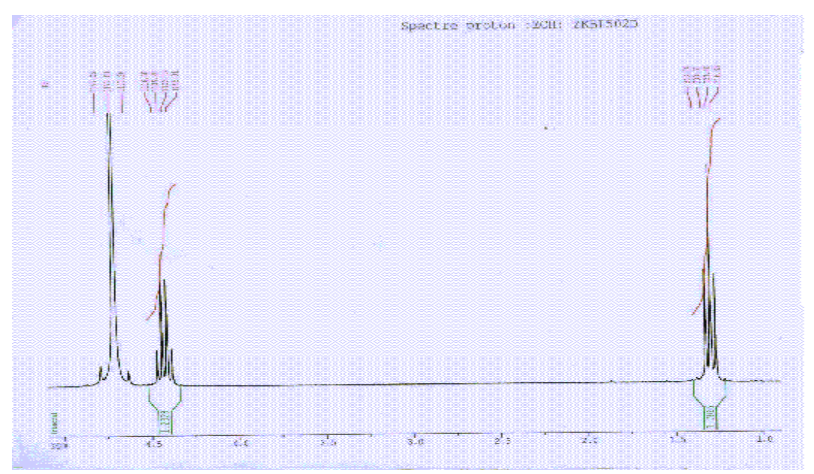

Fig. 4. Spectra RMN1H of potassium ethyl xanthate synthetized (KEX). 


\subsection{Characteristics of Minerals Used: The Case of Crystal}

\section{3.1. Characterization of crystal by infra-red spectroscopy:}

The infra-red spectroscopy plays a very significant role in characterization and identification of minerals, where we have resort to characterize and identify crystal by spectroscopy FTIR in a broad interval (4000-400) $\mathrm{cm}^{-1}$. The infra-red galena spectrum (Figure 5) in $\mathrm{KBr}$ illustrates the appearance of the absorption bands with:

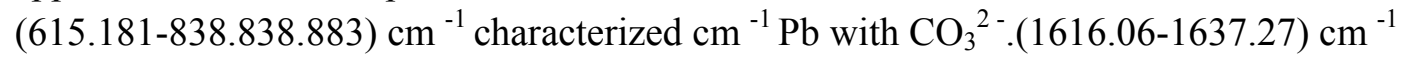
characterized with ions $\mathrm{OH}(\mathrm{M}-\mathrm{OH})$, said water of structure.

(3235.97-3552.24) $\mathrm{cm}^{-1}$ characterized $\mathrm{cm}^{-1}$ grouping $\mathrm{OH}$ of the water of hydration. [23-25]

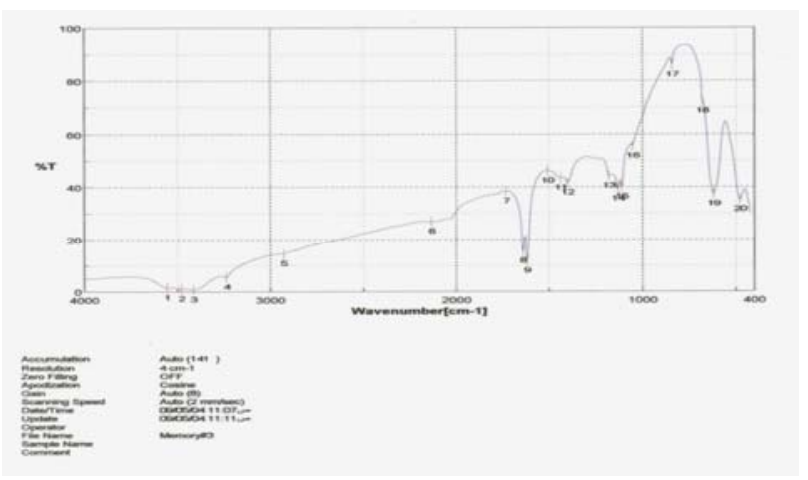

Fig. 5. FTIR Spectrum of the galena.

\subsubsection{Characterization of crystal by X-ray:}

This method is used to identify the crystallized products nature and structure.

According to Figure 6 , there is the diameter $\mathrm{d}_{1}=2.945$ and $\mathrm{d}_{2}=3.405$; the angle $2 \theta_{1}=30.25$ and $2 \theta_{2}=26.17$; (conformed with ASTM files)

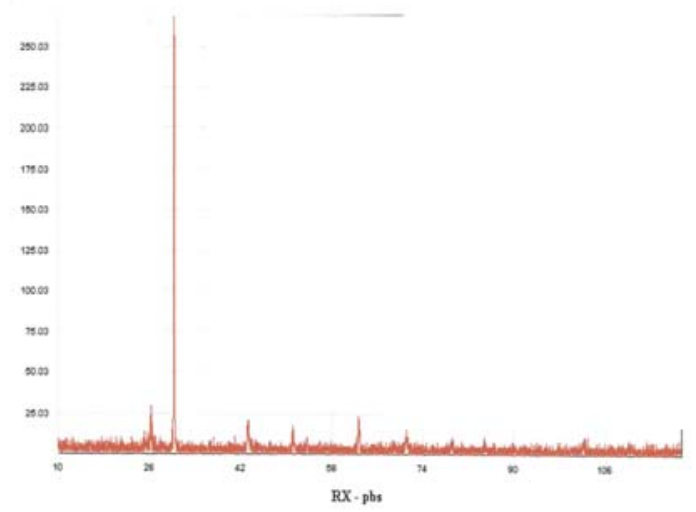

Fig. 6. RX Spectra of the galena. 


\subsection{Theoretical and Experimental Methods Used in Flotation}

\section{4.1. Qualitative determination of the adsorption of the collectors used in flotation:}

The qualitative determination of the adsorption of anion collectors on the mineral surface of crystal (PbS) was made by electronic microscopy has sweeping MEB and by the infra-red spectroscopy, being able to give direct information on the active centers of adsorption. For that we made a comparative study of the images of infra-red MEB and spectra of crystal before and after treatment of this last by the suitable collector under the operating conditions of the process of flotation.

\subsubsection{Qualitative determination of the adsorption of potassium ethyl xanthate (KEX) by infra-red spectroscopy:}

The qualitative study of the adsorption of the collectors on mineral surfaces is an essential factor for the development of technology of enrichment and concentration of the ores by flotation.

The hydrophobicity of surface necessary to flotation is obtained because the big length of hydrocarbon chain of the collectors used, and the concentration of these collectors must remain sufficiently low to avoid the formation of micelles of surface. Indeed if it is formed a second layer on solid surface, it will present the polar part of the collector outside and gives a surface hydrophobia to the solid. This surface hydrophobia will be able to disappear, but the conditions of flotation will remain bad.

During anion flotation, the charge of mineral surface that we need to float, is it the only which must be positive, in order to obtain selectivity between various present minerals.

The qualitative study of the adsorption of ethyl xanthates of potassium prepared starting from carbon bisulphide and a mixture of ethanol and a strong base of potassium hydroxide and water on the level of laboratory, on mineral surfaces of the crystal and iron sulphide required the preparation of a standard solution of concentration $1 \mathrm{~g} / 1$.

For the study of the ethyl adsorption of potassium xanthates on the mineral surface of crystal, we carry out an experiment with a concentration of $1 \mathrm{mg} / \mathrm{l}$ in basic medium $\mathrm{pH}(9-10)$ and to adjust the $\mathrm{pH}$ we used sodium carbonate, and iron sulphide we carry out the experiment of adsorption in an acid medium $\mathrm{pH}(5-6)$ and for adjusted the $\mathrm{pH}$ uses the sulfuric acid (Figure 7).

\section{4.3. Qualitative determination of the adsorption of potassium ethyl xanthate (KEX) on crystal:}

On the infra-red galena spectrum (Figure 7) after treatment by synthesized potassium ethyl xanthate (KEX) by the concentration $1 \mathrm{~g} / \mathrm{l}$ under the conditions of contacts with the atmosphere in basic medium $\mathrm{pH}=9-10$, we note the combination of some peaks of xanthate $\mathrm{PbKX}_{2}$ lead $\left(1210,1110,1020 \mathrm{~cm}^{-1}\right)$ and dixanthogene $\mathrm{X}_{2}\left(1262,1240 \mathrm{~cm}^{-1}\right)$. 
On the analyzed spectrum, we note an average peak to $1128 \mathrm{~cm}^{-1}$ allotted to $\mathrm{PbKX}_{2}$ and the remainder of the characterized peaks $\mathrm{Pb}$ with carbonates.

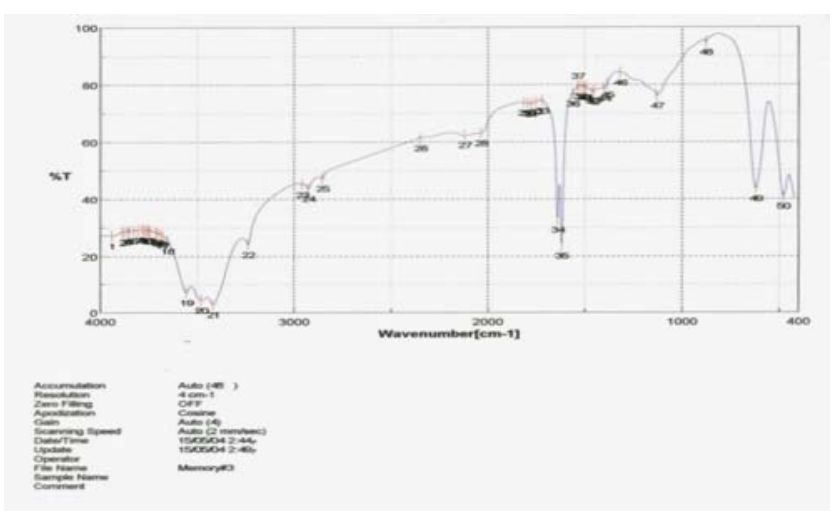

Fig. 7. Spectra FTIR of galena treated by KEX.

\section{4.4. Qualitative determination of the adsorption of xanthate (KEX) by electron microscope with sweeping}

The qualitative study of the ethyl adsorption of xanthate of potassium on the surface of crystal $(\mathrm{PbS})$ by the electron microscope with sweeping (Figure 8-9) with different enlarging treated under the same conditions of the $\mathrm{pH}$ and of concentration show the existence of one or more white stains that means the adsorption of KEX on mineral surfaces. [26-29]

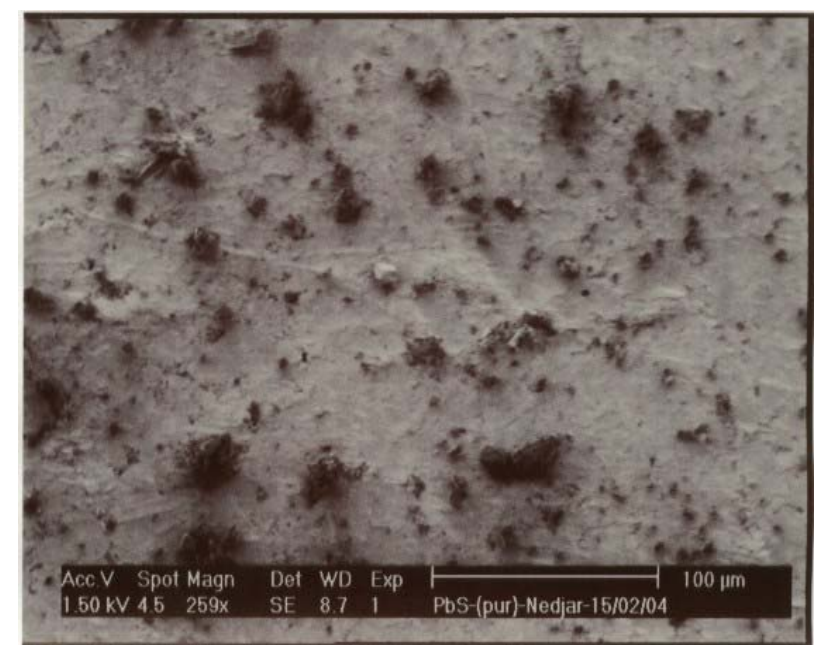

Fig. 8. Microphotography taken with the electron microscope with sweeping (X1480): galena pure. 


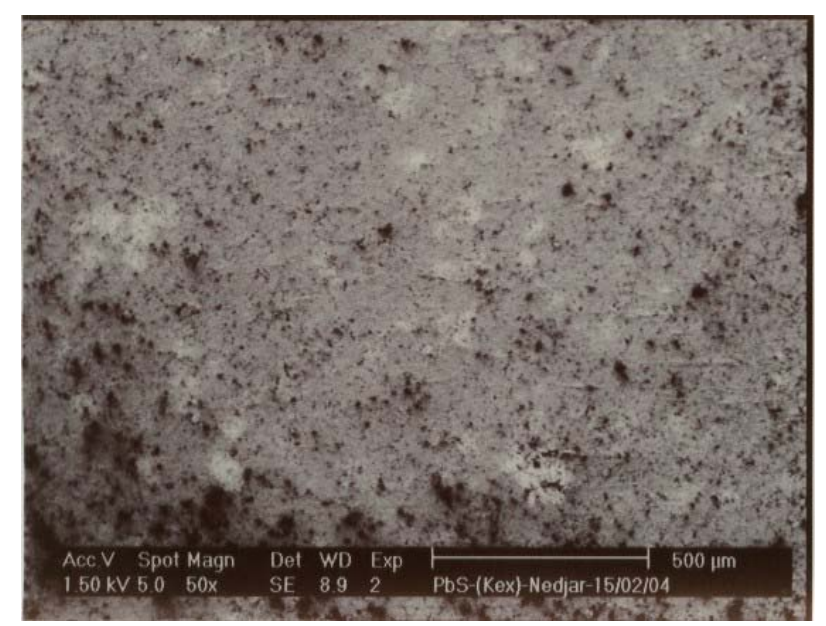

Fig. 9. Microphotography taken with the electron microscope with sweeping (X1480): galena treated by KEX

\section{CONCLUSIONS}

This work enabled us to carry out the organic synthesis of anion collector standard potassium ethyl xanthate (KEX) under determined conditions and the importance of the use of xanthates in the flotation of sulphides.

The qualitative determination of collector's adsorption (KEX) on surface mineral of galena, by IR spectroscopy and electronic scan microscopy (MEB) in different enlarging treated under same the conditions from concentration and $\mathrm{pH}$ made it possible to give direct information on the form of adsorption.

\section{REFERENCES}

[1] Pierre Blazy; El Aid Jdid, Flottation- Mécanismes et Réactifs; Technique d'ingénieur, France, j3350, p.2-7, 1966.

[2] Zongfu D.and John Ralston, Particule-Bubble attachement in mineral flotation ; J.C.I.S, Elsevier Science 217, p.70-76, 1999.

[3] Melik.GayKazyan V.I; Bases physicochimique en théorie de flottation . Moscou, p.22-50, 1983.

[4] RaXtchev A.D.,Nouvelles méthodes physico-chimiques d'étude des minéraux , p.220-221, Moscou."NEDRA", 1989.

[5] AbramovA.A., Ribakov,.V.V, Enrichissement des minerais des métaux nobles et rares dans le pays d'asie, d'afrique et d'amerique latine, Moscou ; p.108-140,1991.

[6] Choubov L.Y., Ivankov S.I, Réactifs de flottation dans les procédés d'enrichissement des minerais, Tom 2, p.180-231., Moscou "NEDRA",1990.

[7] Melik.GayKazyan V.I.,Abramov A.A., Méthodes de recherche dans les procédés de flottation, p.128-138, Moscou."NEDRA", 1990. 
[8] Neeraj K.Mendiratta,Kinetic Studies of Sulfide Mineral Oxidation and Xanthate Adsorption ;Blacksburg,Virginia, p.25-28, May 2000.

[9] Choubov L.Y., Ivankov S.I, Réactifs de flottation dans les procédés d'enrichissement des minerais, Tom 1, p.79-91, Moscou "NEDRA",1990.

[10] Glembotski V.I., Flottation, p.101-110, Mouscou, "NEDRA", 1973.

[11] Eren Cancer ORHAN;Sulfide Flotation; Hacettepe Univercity; Ankara;Turkey, p.1- 5, 15 October 1997.

[12] Ulmann's Encyclopedia of industrial chemistry, $5^{\text {th }}$ Edition , p.10-15, 1988.

[13] Cevher Hazrlama El kitab, Editors;Prof.Dr. Guven Anal, Prof.Dr.Gunduz Ateok,June, p.122-125,1994.

[14] Kelly,E.G, Spottiswood,D.J.Introduction to mineral processing, John Wiley and sons,p.7579, 1982.

[15] Atak,S.Flotasyon IlkeleriveUygulamas; Istanbul Teknik-niversitesi Matbaas;No:101,p.1517, 1974.

[16] NICNAS., Sodium Ethyl Xanthate, Priority Existing Chemical , Secondary Notification Assessment, Report N 5S,p. 20-22, February 2000.

[17] Full public report .Sodium Ethyl Xanthate. Priority exiting chemical N5.Australian [18]government publishing service .Canberra, p.1-16, May 1995.

[19] Sodium Ethyl Xanthate. Chapitre 6, d'autre technique de précipitation .Fin de support 11101-4012., p.116-120, 15 Novembre 2001.

[20] Bartton,D.H.R;Mc combie;S;W;J.Chem.Soc,Perkin trans I,1975,1574-1585.p.7-9,2002.

[21] A .A ., Avdokhin V.M., Oxydation des minéraux Sulfurés dans les procédés d'enrichissement, p. 123-131;161-167, Moscou , Nedra, 1989.

[22] Plousnina I.I., Spectres Infrarouges des Minéraux, Moscou, p.175, 1977.

[23] A.M.Gaudin., Flottation , Memorial Volum ,p.110-112, New York , 1976.

[24] S.Klarck, Mémoire des Constantes Physique des Roches, Mir, p.541, 1969.

[25] Keller W.D., Rickett E.E., Absorption Of Infred Radiation By Powdred Silicamineral, "Amer-Mineral",p.174,1952.

[26] AbramovA.A., Avdokhin V.M., Oxydation des Minéraux Sulfurés dans les Procédés d'enrichissement, Moscou, "NEDRA", p.161-167, 1989.

[27] Bogdanov O.S., Maxinov, Théorie et Technologie de Flottation, Moscou, "NEDRA", p.114-116, 1980.

[28] Abramov.A.A, Modélisation physico-chimique des systèmes de flottation; Moscou, p.6$14,1977$.

[29] Baranov V.F., Guide de Projection des Fabriques d'enrichissement, Tome 1, Moscou, "NEDRA", p.290-293, 1988.

[30] Zard;S;Z;Angew;Chem;Int.Ed;Engl, p.36-672-685, 1997. 